\title{
La antologia como un museo: una aproximación discursiva y pragmática a la conservación y la transmisión de la poesia medieval francesa
}

The anthology as a museum: a discursive pragmatic approach to the preservation and spreading of the medieval French poetry

\author{
Juan Manuel López Muñoz \\ Universidad de Cádiz, Cádiz, España
}

\begin{abstract}
Resumen: En este artículo analizo, desde una perspectiva diacrónica, las formas y las funciones de las prácticas de copia y de compilación que han hecho posible la transmisión hasta hoy de la poesía medieval francesa. Tales prácticas comparten con las prácticas museísticas una misma ambición de conservación y difusión del patrimonio cultural de una comunidad o nación. La transmisión de la poesía medieval no es el resultado de un plan de conservación progresivo, sino que, al contrario, es la consecuencia más o menos azarosa de una suma de proyectos sucesivos, a cargo de una cadena deslavazada de intermediarios. Cada uno de estos intermediarios actúa sobre los textos aplicando sus propias técnicas de selección y de transmisión, según sus propios y objetivos, contribuyendo así con su propia voz a conformar una cierta memoria discursiva del pasado.
\end{abstract}

Palabras clave: Manuscrito. Antología. Poesía francesa medieval. Análisis de discurso. Pragmática. Diacronía.

Abstract: In this article I analyze, from a diachronic perspective, the forms and functions of copying and compilation practices that have ensured the transmission of the medieval French poetry from the Middle Ages to today. Such practices share with museums a similar aspiration to preserve and spread the cultural heritage of a community or nation. The transmission of medieval literature is not the result of some steady conservation plan, but, on the contrary, it is the consequence of a more or less hazardous sum of successive projects, operated by a disjointed chain of intermediaries. Each of these intermediaries works on texts by implementing their own techniques of selection and transmission, according to their own criteria and objectives. While doing it, they contribute, with their own voice, to shape a certain discursive memory of the past. Keywords: Manuscript. Anthology. Medieval French poetry. Discourse analysis. Pragmatics. Diachrony. 


\section{Introducción}

Considerando que las palabras (los enunciados, los textos, los discursos) y los conocimientos que éstas movilizan se encuentran distribuidas en nuestro entorno, uno de los mayores desafíos a los que se enfrenta la lingüística actualmente es conseguir establecer las bases teóricas y metodológicas para implementar, desde una perspectiva interaccionista y «ecológica», el estudio de la relación entre las palabras y sus entornos físicos.

En las últimas décadas hemos asistido a grandes avances en la comprensión de la dependencia entre textos, personas y tiempos. La

Juan Manuel López Muñoz problemática enunciativa, una cuestión tan vieja como los primeros tratados de Retórica, relanzada por los trabajos fundadores de Bajtín, Benveniste, y Ducrot, entre otros, no deja de suscitar preguntas interesantes en la era de la globalización y de las nuevas tecnologías de la información y de la comunicación. Particularmente, por lo que aquí nos concierne, una de estas preguntas, en el corazón de disciplinas como la Pragmática y el Análisis del Discurso, se centra en la manera en que se almacenan y circulan la información y los saberes, ya sea virtualmente (a través de la red de internet) o físicamente (gracias a espacios más o menos institucionalizados), y en la función que cumplen en tal difusión los distintos agentes o mediadores (editores, investigadores, críticos, periodistas, traductores, blogueros y un largo etcétera).

Las investigaciones realizadas y auspiciadas por el grupo CI-DIT desde hace más de una década han demostrado que la circulación de los discursos no es sólo un fenómeno más o menos mecánico de propagación de palabras o de ideas, sino un proceso a la vez transitivo y generativo, que moviliza los saberes pero también los comportamientos y las emociones de personas concretas, en lugares y tiempos definidos, a menudo ligadas a instituciones específicas (LÓPEZ MUÑOZ, 2013a). Mis colegas del grupo CI-DIT y yo mismo hemos definido brevemente la circulación de los discursos como un conjunto de mecanismos de apropiación, re-enunciación y difusión relativamente organizados en determinados espacios por mediadores o "agentes de circulación" específicos para cada uno de tales espacios (LÓPEZ; MARNETTE; ROSIER, 2010). Esta definición reposa sobre varias bases, principalmente sobre las siguientes:

- El estudio de la circulación de los discursos presupone la existencia material de palabras ya dichas (textos, discursos) y de modalidades de propagación de las mismas, incluido espacios de difusión. 
- El estudio de la circulación de los discursos obliga a interesarse por los posicionamientos ideológicos o identitarios (CHARAUDEAU, 2009) de los agentes de difusión, y que se manifiestan principalmente en las posturas enunciativas (RABATEL, 2004) que éstos adoptan en cada acto de difusión.

- El estudio de la circulación de los discursos debe plantearse la cuestión de la legitimidad y de la credibilidad de los textos o discursos que circulan, las cuales dependen estrechamente de la legitimidad y de la credibilidad de los mediadores y de los espacios institucionales en los que se enmarca la actividad de los mismos.

- El estudio de la circulación requiere, en fin, una discusión sobre La antología los efectos pragmáticos de cada acto de difusión sobre los textos, añadiendo una voz (una intención, la del difusor, la del experto y la de la institución que lo sostiene) a la propia voz de los mismos.

Conviene distinguir, en este último sentido, la circulación marcada, que emplea estrategias y espacios más o menos institucionalizados, con lo que esto conlleva de proyecto consciente de difusión, de aquella otra circulación no marcada, que parece seguir unos mecanismos de difusión espontáneos o inconscientes, como los rumores, y en fin de aquel otro tipo de circulación mixta, como en el caso, por ejemplo, de la transmisión de la sabiduría popular o de la literatura de culturas orales, en la que, partiendo de una circulación inicial más o menos espontánea y sin proyecto definido, ésta progresivamente se institucionaliza a través, primero, de los espacios de copia manuscrita y, después, de los espacios de difusión impresa.

Este último tipo de circulación, que es sobre el que se centra particularmente el presente artículo, nos invita a preguntarnos, en primer lugar, sobre las razones que desencadenan un tal mecanismo de difusión aparentemente espontáneo, aunque en cierto modo "necesario", haciendo perdurar unos discursos, unos textos, independientemente de la identidad del autor original y de las intenciones del mismo y, en segundo lugar, sobre las razones que impulsan a los sucesivos mediadores -legitimados como tales por sucesivas instituciones- a seleccionar, clasificar y explicar ciertos textos, en detrimento de otros que son rechazados por distintas razones, para asegurar su conservación y su difusión. Las hipótesis son numerosas, y merecen un análisis preciso. Todas apuntan a la necesidad de revisar el papel 
Juan Manuel

López Muñoz del compilador (entendida esta noción en sentido amplio), con el objetivo de valorar los beneficios y riesgos de su mediación necesaria.

Hasta el momento, pocos estudios se han interesado realmente por la relación entre los espacios institucionales y los discursos que tales espacios contienen y exhiben, más allá de la mera función de conservación. En esta nueva perspectiva, el presente artículo pretende aportar reflexiones que puedan servir para establecer los fundamentos de una nueva comprensión de la función discursiva de los espacios físicos. Concretamente, la hipótesis de partida de este trabajo es que la práctica de la copia de manuscritos y la consiguiente recopilación antológica puede compararse en ciertos aspectos a la labor que desarrollan los museos. Esta metáfora de la antología como museo la tomo prestada de Fraisse (1997, p. 77), quien a su vez se inspiró de Gide -el cual, a su vez, se apoyaba en la misma metáfora defendida por Hofmannsthal- para justificar su rechazo a citar autores considerados "menores". En el prefacio de su Anthologie de la poésie francaise, publicada en 1949 en la prestigiosa colección Bibliothèque de La Pléiade de Gallimard, Gide manifestaba su intención de actuar en su antología como si se tratase del director de un museo, "relegando al sótano aquellas pinturas que no merecen retener la atención del público, de tal manera que las obras expuestas de los artistas seleccionados luzcan mucho más bonitas" (prefacio p. XIII, la traducción es mía).

Así, al igual que un museo, en tanto que espacio continente destinado a la conservación y la exhibición de objetos, implica una labor previa de selección y de rechazo, de clasificación y de organización, del mismo modo las compilaciones de copias manuscritas en la Edad Media y las antologías contemporáneas y posteriores son, a su manera, objetos continentes con un destino semejante que implican acciones similares. La materialidad del nuevo objeto (la copia manuscrita, la compilación, la antología) tanto como el espacio físico donde este se almacena y expone (la biblioteca, el museo) no son meros contenedores donde ciertos actos de comunicación tienen lugar. Al contrario, son los moldes del discurso, fijando la naturaleza del pacto comunicativo, el grado de acuerdo y de esfuerzo cooperativo, marcando regularidades en las relaciones de cantidad, relevancia, y calidad de las palabras (GRICE, 1979). La materialidad física del discurso y los espacios donde se producen confieren o quitan legitimidad, atribuyendo estatus y roles a los distintos participantes, contribuyendo a la construcción de la identidad social (CHARAUDEAU, 2009). Determinados espacios institucionales, 
como por ejemplo las casas de edición, las bibliotecas y los museos, confieren prestigio, autoridad y credibilidad a los discursos que almacenan y/o hacen circular, asegurándoles, en su caso, una extensión amplia o reducida, permanente o temporal. Además, las elecciones de los editores, de los bibliotecarios y de los curadores influyen retroactivamente sobre el prestigio de sus respectivas instituciones y sobre el modo en que los discursos acumulados y expuestos en sus libros y salas influyen, a su vez, sobre los receptores de tales discursos, produciendo, entre otras cosas, un efecto de comunidad discursiva (BEACCO, 2004, p. 117), con un determinado posicionamiento ideológico.

Partiendo de lo anterior, el objetivo principal de este artículo es reflexionar acerca de las consecuencias sobre la memoria discursiva de una determinada colectividad (en este caso, la nación francesa) de acLa antología como un museo ciones aparentemente sencillas como son la conservación manuscrita de la tradición oral y cada acto posterior de recopilación y difusión de la misma, en y a través de espacios institucionales como los museos, las bibliotecas, las universidades, y las escuelas, con las consiguientes maniobras de selección y rechazo que cada uno de tales actos conlleva. Este trabajo es pionero en la manera de abordar la literatura medieval al considerar los efectos de la mediación necesaria de una cadena de agentes de transmisión (autor, juglar, copista, editor, crítico, docente, etc.) y de lugares de copia y difusión.

\section{La memoria de la Edad Media}

Dos problemas esenciales, ligados a la cuestión del tiempo, influyen en la manera en que construimos la memoria de la Edad Media. En primer lugar, la duración del período concernido; en segundo lugar, su enorme distancia respecto al tiempo presente.

Un periodo extenso de tiempo implica evolución, cambios, mientras que todo esfuerzo memorístico tiende, al contrario, a la fijación. Por otra parte, la distancia temporal de varios siglos respecto a ese periodo del pasado opera un importante difuminado sobre los textos que nos sirven de referencia, debido en parte a la extrañeza de la lengua (cuya comprensión requiere una gran formación filológica previa al alcance de pocos expertos) y en parte a la acción necesaria de una larguísima sucesión de mediadores, desde el juglar hasta el lector de hoy en día, con las potenciales modificaciones, accidentales e intencionales que ello conlleva. 
La duración exacta de la Edad Media parece un enigma sin solución. Este hecho en sí mismo tiene consecuencias sobre nuestra percepción actual de tal época. En efecto, según el criterio considerado, la Edad Media parece durar sólo cortos lapsos de tiempo puntuales (la duración de la vida de ciertos hombres ilustres, elevados al rango de modelo, como por ejemplo François Villon) o al contrario extenderse a lo largo más de mil años. Convencionalmente, se considera que la Edad Media ocupa el período de tiempo comprendido entre un momento inicial aproximado coincidente con la caída del Imperio Romano (año 476)

Juan Manuel López Muñoz o, casi cien años antes, con la muerte de Teodosio (año 395 de nuestra era) y un momento final igualmente impreciso, marcado por la invención de la imprenta y la caída del Imperio de Oriente (1453) o, casi cien años más tarde, por la prohibición de la representación pública de los Misterios, en 1548. Por otra parte, si consideramos únicamente criterios lingüísticos, entonces, concretamente la Edad Media francesa duraría menos, en lugar de mil años, unos siete siglos, desde el siglo IX hasta el siglo XV aproximadamente, iniciándose con el primer testimonio escrito en francés antiguo y culminando con los últimos textos en francés medio y el principio de la era preclásica.

La imprecisión que afecta a la Edad Media en tanto que período es fuente de connotaciones negativas y de prejuicios fundados en un error de perspectiva. Uno de los principales prejuicios se manifiesta, de entrada, en el propio nombre "Edad Media". El adjetivo "media" conlleva connotaciones asociadas a la idea de carencia: este adjetivo caracteriza a lo que no es ni viejo ni joven, a lo que no viene antes ni después, a lo que no es ni pequeño ni grande. En ese sentido, se asemeja al concepto de "resto" tal como lo define Baudrillard (1981, p. 207-214). El adjetivo "medio" no tiene opuesto en sentido estricto. Es el resultado de un falso equilibro en una relación polarizada entre lo antiguo y lo moderno. Así, la Edad Media, como concepto, se convierte en una contradicción, desde un punto de vista puramente lógico.

Otro prejuicio aparece en el calificativo dado a la lengua francesa de esta época, en la denominación comúnmente utilizada de "francés antiguo". Lo llamamos así, a pesar de que, paradójicamente, el francés se encuentra en el momento de nacimiento. Este adjetivo es el resultado de una perspectiva que toma como punto de referencia los tiempos modernos, considerados éstos, según la misma lógica paradójica, como una etapa a la vez joven y de plena maduración. La vejez tiene un valor 
negativo en las sociedades actuales, de manera que la producción literaria en francés antiguo no puede desembarazarse de las connotaciones negativas de la senilidad. Los esfuerzos por invertir esta perspectiva son extremadamente raros y encuentran muy poco eco en los medios institucionales actuales. Baumgartner y Ferrand escribieron en 1983 (la traducción es mía): "En el momento de su nacimiento, la lengua francesa era lisa y suave como un guijarro, clara y maleable ${ }^{1 "}$ (p. 15). Sin embargo, esta percepción claramente positiva de la lengua antigua apenas la comparten la mayoría de los editores de textos antiguos quienes, para hacerlos accesibles a un público amplio, se dedican a "rejuvenecer" la lengua y a "restablecer" la ortografía (PERNOUD, 1947, p. 9). EmpezaLa antología como un museo mos ya a entrever, con estos comentarios, la responsabilidad directa de los mediadores sobre los textos que son objeto de sus análisis, así como la responsabilidad que, indirectamente, recae en las instituciones que apoyan y fomentan la recuperación y difusión de los textos medievales.

El prestigio de las bibliotecas que conservan los manuscritos medievales, unido al prestigio del investigador que los traduce y edita, del crítico literario que los comenta y de la colección literaria donde se publican cuenta mucho para la fijación de la memoria del pasado, pues aseguran a los manuscritos una determinada difusión, mayor o menor según los casos. Así, por ejemplo, las antologías de la prestigiosa colección de la Pléiade, publicadas por Gallimard, en formato y con materiales de gran calidad, con hojas cuya textura recuerda no por casualidad a las de los libros sagrados, se encuentran en prácticamente todas las bibliotecas del mundo, principalmente universitarias. En el primero de los dos volúmenes de la Antología de la poesía francesa publicados en esta colección en 2000 (CHAVEAU et alii), consagrado a la poesía de la Edad Media y de los siglos XVI y XVII, los autores declaran sus buenas intenciones en el capítulo de introducción, oponiéndose a la corriente que favorecen ciertas épocas de la poesía (los siglos XVI y XIX) en detrimento de las otras, particularmente de la Edad Media. Sin embargo, si bien estos autores han conseguido equilibrar los espacios relativos que ocupan los siglos XVI y XVII, con alrededor de 300 canciones elegidas para cada periodo, la poesía de la Edad Media mantiene su tradicional posición marginal, con sólo 166 canciones para dar cuenta de un período de siete siglos...

1 «À sa naissance, la langue française était lisse et douce comme un caillou, claire et souple» (BAUMGARTNER; FERRAND 1983, p.15). 
Juan Manuel

López Muñoz

Toda antología supone un acto previo de elección. Algunos textos son retenidos y otros rechazados. Además, la selección de textos producidos por autores distintos en momentos y lugares distintos, ordenados según criterios definidos, genera una especie de conjunto coherente, gracias a las precauciones de los editores y del lector que hace su propio recorrido hermenéutico guiado por sus propias elecciones. A esto se añade la selección de compilaciones que, por su parte, realiza el bibliotecario o el curador de un museo, quien las organizará además espacialmente de un modo significativo en determinadas estanterías o vitrinas y en determinadas salas, más o menos fácilmente al alcance de los lectores o del público.

Muchos de los manuscritos medievales y de las primeras ediciones y compilaciones, antes de ir a parar a una biblioteca pública o a un museo, formaron previamente parte de colecciones privadas, a cargo de ricos bibliófilos. Se da la curiosa circunstancia de que, en lo que se refiere a la Edad Media francesa, muchas de las más importantes colecciones de manuscritos eran propiedad de bibliófilos ingleses.

En Inglaterra, la pasión por los libros ha dominado más que en ningún otro sitio (MEYER, 1876). Richard de Bury, obispo de Durham (†1345), expuso en su Philobiblion los medios de procurarse legajos de manuscritos y las precauciones necesarias para su conservación. Sabemos que Inglaterra y Francia han tenido una lengua común durante cierto período de la Edad Media, además de una historia de relaciones complejas, principalmente bajo la casa de Plantagenet. Muchos manuscritos de textos escritos en ese período, e incluso posteriormente, ya sea en las islas británicas como en el continente, acabaron en manos de poderosos bibliófilos, pagando precios exorbitantes por aquellos manuscritos más preciosos y raros. Tales bibliófilos fueron numerosos y muy célebres: William Gray ( $\uparrow 1478)$, canciller de Oxford y obispo de Ely; Sir Thomas Bodley (†1613), diplomático y profesor en Oxford ; Robert Harley², conde de Oxford y de Mortimer (†1724), Sir Robert Taylor $(† 1788)$; Francis Douce ${ }^{3}(\uparrow 1834)$, anticuario y conservador de manuscritos en el Museo British Museum, etc. Sus colecciones de manuscritos

\footnotetext{
2 Debemos a Robert Harley, a título de ejemplo, la conservación del manuscrito más completo y valioso de los Lais de Marie de France ( $m s$ Harley 978, British Museum).

3 Douce donó unos 19000 libros y 420 manuscritos a la prestigiosa Bodleian Library. Los dos tercios de esta colección son manuscritos medievales y del siglo XVI, entre los que se encuentran numerosos textos en francés antiguo.
} 
constituyen hoy los fondos principales de los más prestigiosos museos y bibliotecas ingleses, gracias a sus generosas donaciones.

La memoria de los orígenes de la literatura francesa (y por ende, de la Edad Media francesa) se encuentra así estrechamente ligada a los gustos y la voluntad de conservación de esos grandes bibliófilos ingleses tanto como al prestigio de las instituciones que hoy acogen sus colecciones. Cabría preguntarse qué habrían podido aportar a nuestra comprensión de la literatura medieval francesa aquellos manuscritos que fueron rechazados por estos bibliófilos, o que quizá se perdieron accidentalmente o que aún duermen en bibliotecas privadas inexploradas...

La antología como un museo

\section{El problema de la voz de los textos anónimos medievales}

La investigación acerca de los beneficios y los riesgos de la acción de

mediadores (personas e instituciones) sobre los textos medievales relanza, con nuevos objetivos, la cuestión de los límites de las voces del texto. ¿De dónde emana la voz (o mejor, de dónde emanan las voces) del texto medieval? ¿Del propio texto o de su entorno?

Antes de intentar responder a estas preguntas, veamos, a título de ejemplo, el curioso problema que plantean ciertas canciones anónimas llamadas convencionalmente por la crítica "canciones de mujer". En este género de canciones, unas características discursivas bastante singulares en el contexto de la Edad Media concurren de tal manera que otorgan a los textos una voz que suena, a partes iguales, femenina, anónima y popular. Este triple timbre resulta, de hecho, de una superposición de criterios diferentes, enunciativos, de autoría y sociológicos respectivamente. Estos tres timbres aparentemente distintos construyen, en cualquier caso, una voz única que se manifiesta en el posicionamiento del poeta para marcar una distancia (sin duda, una oposición más o menos abierta) respecto a la voz dominante en la época, legitimada por las instituciones de entonces tanto como por las instituciones de periodos posteriores hasta nuestros días, y que es, como sabemos, una voz masculina y culta, aristocrática y católica. La crítica distingue así, tradicionalmente, la perfección del Grand Chant de la lírica cortés, de un conjunto heterogéneo de géneros "más fáciles" (FERRAND; SUARD, 1993, p. 16), de temática "ligera" (ROSENBERG; TISCHLER, 1995, p. 11), con voz femenina y popular, marcadas por el hibridismo y el anonimato.

A propósito de las canciones de mujer, Pierre Bec escribió en 1977 : “ce sont des genres variés du registre popularisant, caractérisés 
Juan Manuel

López Muñoz

par un monologue lyrique, à connotation le plus souvent douloureuse, placé dans la bouche d'une jeune fille amoureuse. [...] S'il y a parfois dialogue, il ne saurait s'agir que d'une variante formelle, non essentielle" (1977, p. 57).

Sin poner en duda la erudición de este autor, es interesante señalar, en relación con los objetivos del presente artículo, la acumulación de términos y de expresiones aproximativas (variés, popularisante, le plus souvent, parfois, variante), además de giros negativos (non essentielle, il ne saurait s'agir que), concesivos (s'il y a) e impersonales (placé), que desvelan el posicionamiento del investigador. Tales expresiones subjetivas, que pasan generalmente desapercibidas para un lector no adiestrado en literatura sobre la literatura medieval, construyen una voz (la voz del experto, la voz institucional) que cubre, fertiliza y se combina con la voz (o más bien las voces) del texto medieval, y tanto más cuanto, como en estos casos, éste necesita de la colaboración de intermediarios para poder continuar difundiéndose. Hoy, la voz de las mujeres en las canciones de mujer no se oiría seguramente de la misma manera si se considerara, por ejemplo, que en lugar de haber sido "puesta" en boca de mujeres, se trata de canciones en las que la locutora es una mujer...

Ejemplos como el anterior son muy abundantes, incluso actualmente, volveremos sobre el problema de la responsabilidad de los expertos un poco más abajo. Convengamos ahora, en defensa de este autor, que sus estudios y clasificaciones representaron, a pesar de todo, un progreso histórico respecto a sus predecesores, entre los que los comentarios despectivos de las canciones de mujer funcionaban abiertamente, en contrapartida, como defensa del ideal de escritura masculina medieval. Valga como ejemplo este comentario de Henry Poulaille y Régine Pernoud quienes, a propósito de las canciones de tela ${ }^{5}$, señalaron

\footnotetext{
4 "Se trata de géneros variados del registro popularizante, caracterizados por un monólogo lírico de connotaciones lo más a menudo dolorosas, puesto en boca de una muchacha enamorada. [...] Si a veces hay diálogo, no se trataría sino de una variante formal, no esencial" (la traducción es mía).

5 Las canciones de tela han sido clasificadas por la crítica como subgénero dentro de la clase más extensa (pero en cualquier caso marginal respecto a la tradición lírica medieval) llamada canciones de mujer, junto a otros subgéneros como las canciones de amigo y de malmaridada. Las canciones de tela son composiciones lírico-narrativas cortas, formalmente semejantes a las canciones de gesta, desarrolladas a partir de un exordio más o menos tipificado donde la narración comienza con la presentación de una muchacha noble tejiendo o leyendo en su habitación. Estas canciones son muy raras en dos sentidos: además de por el escasísimo número de piezas conservadas, por el hecho de que el relato está centrado en un breve momento de la vivencia de una mujer, en un contexto literario donde predominan, al contrario, los relatos de las hazañas guerreras o amorosas de hombres nobles (novela y lírica corteses). En las canciones de tela, tras el breve exordio narrativo, el relato se convierte rápi-
} 
(1947, p. Iv) que habrían sido probablemente compuestas por "oscuros juglares itinerantes" ("d'obscurs ménestrels itinérants") y expresarían "el pensamiento de medio letrados" ("la pensée de demi-lettrés"). La oscuridad y la incompetencia de tales poetas explicarían, siempre según estos investigadores, "que no se hiciera caso a sus producciones" (“qu'on n'eût point fait cas de leur production").

La voz femenina de las canciones de mujer ha sido hasta ahora considerada por los expertos unas veces como objeto, otras veces como medio de difusión (mujeres intérpretes) o como destinatario, pero en ningún caso como responsable del texto. En cualquier caso, que sepamos, ningún trabajo ha intentado reflexionar en las formas que adopta esta voz femenina, en sus funciones discursivas y en los efectos pragmáticos que pudieron cumplir en su contexto literario, social e histórico. Tales La antología como un museo manifestaciones de la voz de las mujeres, en una época en la que los historiadores la definen como poco audible, ¿estarían ligadas a una especie de movimiento proto-feminista? ¿Podría haber funcionado esta voz femenina, popular y anónima como denuncia de la situación de una colectividad oprimida? ¿Se trataría de un discurso más o menos utópico, orientado contra una sociedad patriarcal dirigida por la aristocracia y la religión católica? ¿O bien, simplemente, de un discurso constructor de una nueva tradición literaria, como alternativa a los géneros dominantes?

Preguntas como éstas son las que ponen de relieve la necesidad de afrontar en adelante el estudio de las voces del texto, incluidas las de los expertos y otros agentes de difusión, con una metodología multidisciplinar (LÓPEZ MUÑOZ, 2013b). Pues se trata de comprender el concepto de voz en todas sus dimensiones (también pragmática), precisando en primer lugar su relación respecto a las nociones de punto de vista, posicionamiento, identidad y subjetividad. La revisión del concepto de voz debería también conducirnos a investigar su componente no verbal así como su relación respecto al silencio, la negación, los implícitos y los no-dichos.

Desde el ángulo literario, la voz debe concebirse a la vez como punto de origen y de destino, al tratarse de una literatura orientada hacia un público, dado que esta voz se construye en cada acto de recepción; todo ello sin olvidar que durante el trayecto hasta su destinatario se requiere la participación de intermediarios (personas y espacios). A

damente en un discurso directo de la joven protagonista, quien reflexiona y se lamenta de su soledad y frustración debido a su situación de víctima de la opresión paterna, conyugal o de la sociedad en general. 
Juan Manuel

López Muñoz nivel semiológico, sin dejar de reconocer la importancia de la transición entre una cultura oral y otra escrita durante la Edad Media, en lo que concierne a la definición de la voz, no podemos perder de vista la parte gestual ligada al acto de transmisión oral (performance de la canción o de la lectura en voz alta por el intérprete) y el componente visual del manuscrito. Por el lado lingüístico, muchos aspectos de las teorías de la enunciación, en particular aquellos relativos a la noción de borrado enunciativo (RABATEL, 2004) pueden ayudar a la exploración de la interrelación de las distintas voces dentro del texto y a encuadrar con nuevos criterios el problema del anonimato en la Edad Media. El recurso, además, a los marcos teóricos y metodológicos del análisis del discurso y de la pragmática me parece indispensable, con el fin de dar cuenta de la interrelación entre el texto medieval y su entorno (de entonces y de ahora), incluido espacios, soporte material, técnicas y personas que participan no sólo en la producción de los textos sino también en su estudio, clasificación, transmisión, almacenamiento y exhibición.

De hecho, la principal dificultad de la noción de voz textual es que generalmente no corresponde a un único individuo, ni siquiera en el caso de los textos firmados por un autor reconocible y reconocido, sino que, al contrario, corresponde a una entidad transindividual y multisubjetiva, desde el momento en que la voz se construye precisamente en la interacción con otras voces que cohabitan el mismo texto, procedentes de otros textos o del entorno del texto, en un juego permanente de acercamiento (identificación con sus semejantes) y de distanciamiento (alteridad), siguiendo una dinámica que va desde el borrado enunciativo más o menos total hasta la hipermarcación, desde la coenunciación a la subordinación (infraenunciación) o al contrario a la dominación (supraenunciación) de una voz respecto a otra.

La tarea de delimitar una voz en un texto se complica mucho más cuando se trata de una obra medieval, por el hecho de que ambas evolucionan conjuntamente a lo largo de un eje diacrónico y diatópico, sin contar con los problemas derivados de los imponderables de la transmisión (manipulaciones, lagunas, etc.). Además, al problema del referente inaccesible del autor anónimo se añade la potencialidad del yo lírico a ser asumido alternativamente por una cierta colectividad de poetas. De todo ello resulta que la voz del texto medieval constituye, por decirlo así, una especie de nube de voces, de una manera parecida - me disculpo de entrada por esta comparación extravagante - a como está 
constituida la capa de electrones de los átomos, en el sentido en que se trata de una nube muy dinámica, con continuos pasos de un nivel a otro.

En efecto, tomando como ejemplo las canciones de mujer medievales -pero este ejemplo es seguramente extensible a cualquier otro tipo de texto medieval- podemos distinguir al menos cuatro capas distintas de voces, interconectadas entre sí:

1) En el nivel extratextual se sitúan las voces que intervienen, consciente o inconscientemente en cada re-producción de una canción, durante el proceso de transmisión oral así como durante el proceso de copia manuscrita, además de a lo largo de su difusión hasta nuestros días por intermediación de numerosas personas (libreros, bibliófilos, filólogos, editores, enseñantes, respon-

La antología como un museo sables de bibliotecas y museos, etc.), cada uno con sus propias técnicas y con sus propias intenciones. Es importante señalar en este aparado, por lo que interesa al objetivo general del presente volumen de Letras, que la literatura medieval nació por y para la legitimación de las jóvenes lenguas vulgares recientemente desgajadas del latín. Así, las voces de estas personas que operan a nivel extratextual (me refiero especialmente ahora a copistas, libreros y biblióficos) pudieron contribuir a la construcción y a la defensa de la identidad discursiva y de la memoria discursiva de la naciente comunidad y de sus nuevas instituciones, al seleccionar para conservar y difundir textos de una determinada voz (la voz francesa, la voz anglonormanda, etc.) como forma de oposición más o menos abierta respecto a la voz dominante (la de la cultura latina y católica). La voz de la literatura francesa medieval se encuentra así estrechamente ligada a la de sus mediadores. Sabemos también que una segunda fase importante de recuperación y difusión de textos antiguos tuvo lugar durante el Romanticismo, época en la que sus mediadores (así como los espacios institucionales que les sirvieron de promotores) cumplieron un indudable papel en la construcción y defensa de las identidades nacionales. Sabemos también, en fin, que los grandes filólogos de la primera mitad del siglo XX se nutrieron de las ideas del Romanticismo.

2) En el nivel paratextual, intervienen las voces de aquellos que leen en voz alta, cantan y escenifican, dando cuerpo y sonido, y 
Juan Manuel

López Muñoz

enriqueciéndo con gestos y silencios, a las voces del texto medieval. La literatura medieval en sus orígenes no estaba concebida para la lectura individual y silenciosa. Las canciones de mujer eran monódicas, de manera que, independientemente del género sexual de quien las compusiera, en la voz del intérprete o de la intérprete resonaban las voces de los distintos personajes masculinos y femeninos.

3) En el nivel intertextual interactúan las voces provenientes de los condicionamientos de género discursivo, además de aquellas que resuenan en los préstamos, en casos de parodias más o menos explícitas, de pastiche y de hibridación. La autonomía enunciativa de ciertos fragmentos (particularmente los estribillos) los hacía muy aptos para la dislocación y, por consiguiente, para la circulación intertextual. Por otra parte, la práctica común de la imitatio y de la variatio construye una voz cuyos límites aparentemente evanescentes se dibujan con claridad no en el interior del texto sino en la red intertextual.

4) En el nivel textual, por último, la polifonía textual conlleva la fragmentación de la voz del texto en una fragmentación de voces interactivas. En las canciones de mujer, el primer desdoblamiento tiene lugar entre el poeta anónimo y la figura también anónima del narrador que cuenta las vicisitudes de la joven heroína (ésta con nombre propio, aunque no siempre). Después, el desdoblamiento del narrador en la figura de la heroína, borrándose enunciativamente, para asegurarse de que la voz de la joven se expresa de la forma más libre posible (Discurso directo libre, discurso indirecto libre).

\section{El acto de recopilación en la Edad Media: el ejemplo de los Lais Marie de France}

Todos los medievalistas están de acuerdo en que, en el paso de la literatura oral a la escrita en la Edad Media, se produce un hecho capital: el acto de copia. Pero este acto es mucho más complejo de lo que podría parecer, pues cualquier re-producción de un texto en un contexto diferente y en un soporte material diferente conlleva, se quiera o no, una alteración (PEYTARD, 1993, GENETTE, 1994, p. 29). Scripta manent: la escritura fija y conserva; pero tambien scripta meliorant: la escritura es la ocasión de una reelaboración (CERQUIGLINI, 1987). Y el hecho más 
relevante quizá, que hasta ahora ha retenido muy poco la atención de los investigadores, es que las copias eran, además, generalmente reunidas en cancioneros o compilaciones, donde textos a veces de distintos géneros (literarios, científicos, filosóficos, etc.) e incluso en distintas lenguas, se sucedían en cierto orden, enriqueciéndose de significados recíprocamente.

La recopilación, aunque necesariamente posterior al acto de copia, no debemos entenderla como una consecuencia de éste, sino que, la mayoría de las veces, sucede al contrario: existe un proyecto previo de recopilación que implica una búsqueda y unos determinados mecanismos de selección de los textos para copiar. La recopilación de manuscritos implica un principio organizacional pero también una finalidad. Al agrupar un cierto número de textos se crea un objeto material diferente, con una nueva dimensión discursiva (FRAISSE, 1997, p. 3).

En el prólogo de los Lais de Marie de France, la autora tomó la precaución de indicar su función mediadora como parte de una cadena preexistente de difusión de la materia bretona. Según Marie de France, los lais habían sido compuestos por los Bretones con la finalidad de la remembrance de las leyendas del pasado que ellos mismos habían oído contar. En una especie de acto de bautismo (KRIPKE, 1985, p. 84-85), Marie de France recopila estos lais, con la intención de que tal cadena de difusión no se rompa (la traducción es mía):

He pensado en los lais, de los que había oído hablar. No lo dudaba, bien sabía que los compusieron y los difundieron para recordar el pasado. He oído narrar muchos, no quiero dejarlos pasar ni olvidar ${ }^{6}$ (Prólogo, versos 33-40).

La finalidad del acto de copia y recopilación que la autora emprende, es, pues, explícitamente, la preservación de las leyendas bretonas. Marie de France insiste además en la función prospectiva de la conservación de tales leyendas, lo que es, en mi opinión, un detalle fundamental. Pues su acto de recopilación parece, en efecto, especialmente destinado a sus lectores futuros, a quienes reconoce una mejor

6 «Des lais pensai qu'oïz aveïe. / Ne dutai pas, bien le saveie, / que pur remembrance les firent / des aventures qu'il oïrent / cil ki primes les comencierent / e ki avant les anveierent. / Plusurs en ai oïz conter, / nes vueil laissier ne obliër ", según la edicion de Karl Warnke, Lais de Marie de France, 1990, Paris, Librairie Générale Française (Livre de Poche). 
Juan Manuel

López Muñoz

capacidad para leer entre líneas que a sus contemporáneos, como ella misma indica en su prólogo:

Los Antiguos acostumbraban, como atestigua Prisciano, a expresarse en sus libros con mucho hermetismo, para aquellos lectores del futuro, que debían estudiarlos, pensando que éstos podrían interpretar los escritos y añadirles los nuevos conocimientos que tuviesen. Los filósofos lo sabían y comprendían ellos mismos que, cuanto más tiempo transcurriese, los hombres tendrían una inteligencia más sutil y serían capaces de recoger aquello que era necesario transmitir7. (Prólogo, versos 9-22).

Al "relanzar" de esta manera la materia de Bretaña, María de Francia ha contribuido a su conservación con gran éxito hasta nuestros días, como sabemos. Ahora bien, la misión que ella misma se asignó no era la de simple copista, sino la de trovadora (literalmente: "la que encuentra"): esto la autorizó a inventar, reformular, manipular...

De hecho, un estudio pormenorizado de estos cuentos bretones revela que estaban compuesto de un conglomerado de motivos y de temas procedentes de distintas tradiciones, principalmente celta, pero también normanda, hebraica, provenzal y griega (LÓPEZ MUÑOZ, 2008, p. 31). La intención de Marie de France era, seguramente, menos inocente de lo que podemos creer, pues, en un contexto donde dominaba - como la autora misma señala explícitamente -, un sincretismo de tradiciones romana y francesa (materia cortés y carolingia) ampliamente instituido, Marie de Francia pudo servir, intencionalmente o no, de propagandista de un nuevo poder, el imperio angevino, al rescatar (y a la vez construir) un pasado literario común a un lado y otro del Canal de la Mancha, y proyectarlo hacia el futuro.

Este caso ejemplar de los Lais de Marie de France demuestra que todo acto de recopilación de textos (por extensión, un museo implica también un acto a gran escala de recopilación) debe ser concebido como una forma de creación: el resultado en un texto significante global, con una finalidad determinada, y no una simple suma o acumulación de tex-

7 «Custume fu as ancïens,/ Ceo testimoine Precïens,/ Es livres ke jadis feseient,/ Assez oscurement diseient/ Pur ceus ki a venir esteient/ E ki aprendre les deveient,/ K’i peüssent gloser la lettre/ E de lur sen le surplus mettre./ Li philesophe le saveient,/ Par eus meïsmes entendeient,/ Cum plus trespassereit li tens,/ Plus serreient sutil de sens/ E plus se savreient garder/ De ceo k’i ert a trespasser», según la edición de Karl Warnke, Lais de Marie de France, 1990, Paris, Librairie Générale Française (Livre de Poche). 
tos. El copista, como el juglar, al reunir textos en un mismo libro, actúa como un editor (HUOT, 1987), cuando no directamente como autor (como hemos visto en el caso de Marie de France). Una vez recopilados los textos, el resultado es un texto completo, incluso si el proyecto de compilación hubiese quedado inconcluso, aceptemos la paradoja.

Este problema es sin duda mucho más complejo en la Edad Media. Pues, en muchos casos, las compilaciones de copias sufren modificaciones sucesivas a cargo de copistas sucesivos, no necesariamente con un proyecto de recopilación común, es decir, no necesariamente con los mismos criterios ni con las mismas intenciones, al contrario de lo que suele ocurrir en las recopilaciones de textos y en las antologías producidas a partir del Renacimiento.

La antología como un museo

\section{Breve historia de las antologías de la poesía medieval francesa}

En tanto que a la vez objeto y acto literario, la antología de poesía francesa medieval (y, en general, cualquier otro tipo de antología) está sujeta a su propia evolución histórica.

Podemos distinguir cuatro fases principales en esta evolución, que se caracteriza, como veremos, no por una progresión lineal sino, como suele suceder en la Historia, por una dinámica circular basada en las idas y vueltas de dos principales tendencias: una tradición que llamaremos "femenina", de enfoque mundano, que promueve el placer, la belleza, las emociones y las ideas; y una tradición "masculina", culta, que persigue la educación, la normalización, la clasificación, el saber y la razón.

En una primera fase histórica, al final de la Edad Media, la práctica de la antología mira sobre todo hacia el futuro, atendiendo no obstante al presente, como nos hizo comprender la recopilación de cuentos bretones emprendida tempranamente por Marie de France. La compilación se concibe como un conjunto inacabado, objeto de potenciales modificaciones y añadidos. Aunque, por supuesto, funciona como archivo contra el olvido, no es un libro de biblioteca en sentido estricto, quiero decir, no es un objeto de lujo, sino al contrario un libro para usar. Estas antologías son, algunas veces, la obra de una sola persona, como es el caso, por ejemplo, del livre de Pensée de Charles d'Orláns (ms 25458 BNF). Autógrafo en parte, este manuscrito recopila tanto baladas propias como composiciones de poetas invitados a la corte de Blois. Sin embargo, la mayoría de las veces, estas compilaciones son el resultado de la 
Juan Manuel

López Muñoz

100

acción sucesiva de varias personas, a lo largo de un tiempo generalmente largo. Tal es el caso, por ejemplo, del llamado Chansonnier de Saint Germain des Prés ( $m s 20050$ BNF), iniciado en la segunda mitad del siglo XIII, donde se aprecian al menos tres manos principales sucesivas, además de varios añadidos en épocas muy posteriores (ZINK, 1977, p. 21). Otro ejemplo notable es el manuscrito Douce 308, elaborado a principios del siglo XIV. Este manuscrito se compone de 5 libros, de los cuales 4 libros de prosa y un cancionero (llamado Chansonnier d'Oxford), realizado a principios del siglo XIV. Este quinto libro, el cancionero, contiene 521 canciones organizadas por géneros. Un estudio relativamente reciente hecho por Mary Atchison (2005) revela que el manuscrito fue elaborado por un equipo de copistas siguiendo un plan detallado de edición. Además, la organización de los textos por géneros muestra la comprensión de esos copistas acerca de las diferentes formas poéticas.

Tras la Edad Media, las antologías poéticas son editadas por libreros de reconocido prestigio. Conservando aún su función prospectiva (conservar para el futuro), la práctica de la recopilación está sin embargo marcada por la melancolía del pasado, considerado en ciertos aspectos mejor que el tiempo presente. De enfoque principalmente pagano y hedonista, la antología se concibe como un objeto de placer pero también de conocimiento. Se persigue suscitar la admiración por la elevación de los sentimientos y de las ideas que los poetas del pasado expresaban con mayor precisión y libertad. El ejemplo de antología más notable de esta época es quizá el Jardin de Plaisance et fleur de Rhétorique, publicado en 1501 por el librero Antoine Vérard. Esta antología fue objeto de numerosas imitaciones posteriormente. En 1573, el librero Pierre L'Huilier publicó en París una antología cuyo título decía elocuentemente : Recréation et passetemps des Tristes, pour resjouyr les mélencoliques, lire choses plaisantes, traictans de l'art d'aimer, et apprendre le vrai art de la poësie. Esta antología se compone de 418 piezas, de las que un poco más de la mitad provienen de antologías anteriores, en concreto 44 de ellas estaban ya incluidas en el Jardin de Plaisance de Vérard (FRAISSE, 1997, p. 29). De una antología a otra, es frecuente en efecto que aparezcan las mismas canciones. Tal dinámica de la repetición favorecerá, como veremos, en la fase inmediatamente posterior, la constitución de modelos de discursos poéticos ejemplares, con consecuencias muy importantes para la memoria literaria de la Edad Media que domina en nuestros días. 
En la tercera fase histórica, la práctica de la antología persigue, en efecto, promover la idea de " excelencia » (noción tan de moda hoy en día), destacando la producción de uno o varios poetas considerados ejemplares, alrededor de los cuales giran de forma más o menos claramente jerarquizada las figuras de otros poetas contemporáneos. La antología ya no mira para el pasado ni apenas para el futuro, sino para el tiempo presente, poniendo en marcha estrategias conscientes de olvido. En esta época, la literatura anterior a Malherbe no se considera digna de ser recopilada. El hedonismo está formalmente excluido. Al contrario, la antología adquiere fuerza de legitimación, respaldada por el poder institucional. Su finalidad es normativa y educativa: depuración del lenguaje, fijación de formas de composición literaria, etc. Por decirlo brevemente, la antología poética en este periodo se asemeja a una

La antología como un museo especie de galería de personalidades. Un ejemplo evidente es Recueil des plus beaux vers des Messieurs de Malherbe, Racan, Monfuron, Maynard, BoisRobert, L'Estoile, Lingendes, Toussaint, Mottin, Mareschal et autres des plus fameux esprits de la Cour, publicado por Toussaint de Bray en 1626-1627. El efecto de lista y de catálogo normativo se deduce ya del propio título.

La cuarta fase histórica, en fin, se caracteriza por una voluntad de totalización erudita, por momentos fuertemente marcada por la tradición romántica y positivista (en el sentido del segundo Comte). En la época de las grandes expediciones científicas y arqueológicas, la práctica de la antología se une a este esfuerzo común de historización y de acumulación de objetos del pasado que impulsa, a veces, más la curiosidad religiosa o gnóstica que el saber racionalista. Las antologías de esta época parten de un resurgimiento de la tendencia femenina y hedonista. En 1765, Jean Mounet publica en París la Anthologie françoise ou chansons choisies depuis le XIII siècle jusqu'à présent, avec une Mémoire historique sur la chanson française par M. de Querbon, plus un "Choix de chansons joyeux " par C. Colle et un supplément "Chansons gaillardes". Las estrategias de olvido que caracterizaron la fase precedente dejan paso a maniobras de recuperación (eso sí, muy selectivas) de la poesía del pasado medieval, con fines identitarios : a través de la voz de los poetas del pasado se pretende reconstruir la historia y el "genio" de la comunidad cultural que la produce. Progresivamente, esta búsqueda identitaria se impregna de una misión educativa. La tendencia femenina inicial se invierte y la práctica de la antología poco a poco parece funcionar de modo cada vez más semejante a un museo, como lugar de almacena- 
Juan Manuel

López Muñoz

miento (conservación de recuerdos) y como espacio de clasificación (organización, relación de los distintos ítems para que sean comprendidos mejor y puedan recordarse mejor), con fines placenteros (dado que las emociones permiten fijar mejor los recuerdos) y didácticos. Así, incluso aquellas antologías que se presentan como invitaciones al placer de leer y de (re)descubrir el pasado literario (sobre todo aquellas de la primera mitad del siglo XX), se aseguran de introducir los textos recopilados con un prólogo razonado y justificado, orientando la lectura.

La antología de Poésie médiévale française publicada por Pernoud en 1947 en las ediciones du Chêne es un ejemplo curioso, al manifestar el punto de vista reivindicativo del autor (seguramente compartido por la institución que lo sostiene). En el prólogo, Pernoud declara su intención de poner fin a la idea generalizada de que Villon es el primer poeta de la literatura francesa y, dicho esto, no sólo lo elimina directamente sino que, comenzando la antología por Christine de Pisan, ordena los textos en una cronología intencionalmente inversa respecto a la tradicional, desde el final de la Edad Media hacia atrás en el tiempo, justificándose en el principio pedagógico que consiste en avanzar desde lo más conocido a lo menos conocido (1947, p. 10). Con un posicionamiento diametralmente opuesto, apenas dos años después, en 1949, Gide publica la Anthologie de la poésie française (mencionada al principio del presente artículo). En el prólogo, el autor, tras declarar haber "naturalmente" atendido a sus propios gustos (p.xiII), restablece el orden cronológico y restituye a Villon su rol ejemplarizante "dentro del extraordinario caos pseudo-poético en el que surgió nuestra lengua" (p. xiv), semejante a una estrella "en esta vía láctea con luces apagadas" (p. xiv). Curiosamente, Gide no cita a Christine de Pisan.

Desde los años 60-70 y hasta nuestros días, la función didáctica prima sobre las demás, a medida que los criterios de selección y de rechazo se fundan sobre juicios menos subjetivos. Las palabras "gusto" y "placer" desaparecen prácticamente de los prefacios. Los limites entre antología, estudio de géneros de discurso y edición critica son difusos, sobre todo en el caso de los textos medievales. Uno de los ejemplos mas destacados en este sentido es la antología realizada por Pierre Bec en 1977-1978, bajo el título de: La Lyrique française au Moyen Âge (XII et XIII siècles). Contribution à une typologie des genres poétiques médiévaux. El título rotula elocuentemente la función crítica, explicativa y clasificadora de esta antología. El espacio habitualmente destinado al prefacio en las antologías se extiende 
en este caso hasta ocupar la totalidad de un primer volumen separado, mientras que la antología propiamente dicha ocupa un segundo volumen. Es curioso señalar que, parejamente a este gran desarrollo de las introducciones explicativas de las antologías, en los museos, los paneles con textos explicativos de las obras expuestas van ocupando progresivamente un espacio mayor y más destacado en cada sala.

En este último período, la poesía medieval aparece cada vez más como un objeto de estudio, y no de placer, destinada a especialistas vinculados a espacios institucionales de enseñanza, escuelas y sobre todo museos y universidades. Las antologías de poesía medieval siguen una gran diversidad de criterios más o menos rigurosos: temáticos (JONIN, 1991), geográficos (FERRAND; SUARD, 1993), discursivos (ROSENBERG; TISCHLER, 1995), etc. Los textos se acompañan de abundantes notas cri-

La antología como un museo ticas y bio-bibliográficas (CHAUVEAU et alii, 2000). La mayoría de tales antologías se presentan ellas mismas explícitamente como un útil especialmente concebido para la enseñanza (THIRY, 2002).

\section{Conclusión}

En tiempos muy recientes, el desarrollo de algunas ramas de la lingüística, como la tecnología discursiva (PAVEAU, 2007), ha permitido mejorar nuestros conocimientos acerca de cómo la materialidad de los objetos que sirven como contenedor o como soporte de la comunicación humana determinan los discursos que éstos sustentan, así como su interpretación, funcionando como parámetros de la cognición. Sin embargo, a estas investigaciones les queda mucho camino por recorrer. Sabemos que todo discurso conlleva una dimensión plurisemiótica, pero estamos aún lejos de haber sistematizado las relaciones que mantiene la parte no verbal - y concretamente en este caso, la materialidad del soporte físico del discurso y la del espacio donde éste se encuentra - con la parte verbal.

De los scriptoria de las abadías a las bibliotecas, museos y casas de ediciones actuales, los sucesivos espacios constituyen un tipo de materialidad profundamente ligada a las prácticas de construcción de la memoria de un determinado grupo o nación. Se trata, en efecto, de espacios de copia y de selección, conservación, clasificación y difusión de los textos, pero también de espacios de elaboración de una memoria discursiva que otorga a su vez a dichos espacios una determinada identidad (PAVEAU; ROSIER, 2010). Fijar, salvar del olvido, pero tam- 
Juan Manuel

López Muñoz

104

bién, reformular, organizar, clasificar, analizar, traducir, comprender, denunciar, persuadir, educar... todas estas acciones pudieron motivar el acto de copia manuscrita y de recopilación posterior.

En este artículo hemos partido de la comparación de la antología como un museo. Salvando las diferencias, esta comparación ha permitido abordar el problema de la relación entre "continente" y "contenido", entre espacio y discurso, entre materialidad y significado, la cual se teje, la mayoría de las veces, a través de la intervención de determinadas personas instituidas socialmente como mediadores o agentes de difusión.

En el caso de la poesía medieval, debido a sus condiciones particulares de producción y de difusión, unido a la distancia temporal respecto al momento presente y al extrañamiento que producen las lenguas antiguas, la figura del mediador aparece como necesaria, en el sentido estricto de este adjetivo. Sobre estos mediadores recae por tanto una gran responsabilidad. De tipos muy diferentes (juglar, copista, bibliófilo, editor, investigador, etc.), cada uno con sus propias técnicas y sus propios criterios y objetivos, ellos han hecho (y aún hacen) posible que los textos medievales, muchos procedentes de la tradición oral, sean accesibles a un lector de nuestros días, lo que podría parecer en cierto modo milagroso - teniendo en cuenta la ausencia de un proyecto inicial definido conservación -, pero obviamente no lo es.

Al conservar los textos y difundirlos, cada mediador deja una huella más o menos visible en ellos, inevitablemente. Pues una cadena de transmisión de tal longitud y naturaleza, capaz de hacer viajar un texto desde tiempos remotos hasta nuestros días, implica una suma de voluntades, o lo que es lo mismo, una suma de intenciones, a veces incluso opuestas.

Hablar de la función discursiva de los espacios de difusión nos ha llevado naturalmente a abordar también la cuestión de los territorios lingüísticos. Como señalé más arriba, resulta muy interesante el hecho de que un gran número de textos franceses medievales fueron copiados, reunidos y conservados por primera vez en territorios periféricos, más o menos alejados de los centros de producción, donde el francés no era (o ya no era) lengua materna (Inglaterra, Italia), en lugares específicos que funcionaban a la vez como espacios de socialización, de mediación cultural (traducción) y de encuentro de saberes.

Sin pretender haber aportado conclusiones definitivas acerca de las consecuencias sobre los textos literarios del pasado (sobre la re- 
cepción de los mismos, principalmente) de la intervención de los espacios y agentes que se encargan de su conservación y difusión, espero no obstante que las reflexiones que presento en este artículo puedan contribuir a sentar las bases para un reexamen de las relaciones entre la memoria y la innovación en el contexto actual marcado por importantes mutaciones tecnológicas y las consiguientes nuevas dinámicas memorísticas. Preguntarnos sobre los efectos discursivos y pragmáticos de los actos de los copistas y de los antólogos puede conducirnos a reconsiderar el papel de los otros tipos de mediadores del texto medieval y de los espacios que lo albergan.

\section{Referencias}

ATCHISON, Mary. The chansonnier of Oxford Bodleian MS Douce 308: essays and complete edition of texts. Aldershot: Ashgate Publishing, 2005.

BAUDRILLARD, Jean. Simulacres et simulation. Paris: Galilée, 1981.

BAUMgARTNER, Emmanuèle; FERRAND, Françoise. Poésies d'amour des $\mathrm{XII}^{\mathrm{e}}$ et $\mathrm{XIII}^{\mathrm{e}}$ siècles. Paris: Union Générale des Éditeurs, 1983.

BEACCO, Jean-Claude. Trois perspectives linguistiques sur la notion de genre discursif. Langages, v. 38, n. 153, p. 109-119, 2004.

BEC, Pierre. La lyrique française au Moyen Âge (XII ${ }^{\mathrm{e}}$ et $\mathrm{XIII}^{\mathrm{e}}$ siècles): contribution à une typologie des genres poétiques médiévaux. Paris: Picard, 1977-1978. v. 1: Études, v. 2: Textes.

CERQUIGLINI, Jacqueline. Quand la voix s'est tue: la mise en recueil de la poésie lyrique aux $\mathrm{XIV}^{\mathrm{e}}$ et $\mathrm{XV}^{\mathrm{e}}$ siècles. In: BAUMGARTNER, Emmanuèle; BOULESTREAU, Nicole (Ed.). La présentation du livre. Actes du colloque Paris-X Nanterre du 4 au 6 décembre 1985. Paris: Centre de Recherches du Département de Français de Paris-X Nanterre, 1987. p. 313-327. 
CHARAUDEAU, Patrick. Identité sociale et identité discursive: un jeu de miroir fondateur de l'activité langagière. In: (Dir.). Identités sociales et discursives du sujet parlant. Paris: L'Harmattan, 2009. [en ligne].

CHAUVEAU, Jean-Pierre; GROS, Gérard; MÉNAGER, Daniel. Anthologie de la poésie française: Moyen Âge, XVIe siècle, XVIIe siècle. Paris : Gallimard, 2000; 2009. (Bilbliothèque de la Pléiade).

Juan Manuel López Muñoz

MAINGUENEAU, Dominique. Analyse du discours et archive. Semen, n. 8, 1993. [en ligne].

FERRAND, Françoise; SUARD, François. Quatre siècles de poésie: la lyrique médiévale au Nord de la France du XIIe au XIVe s. Troesnes: Corps 9, 1993.

FRAISSE, Emmanuel. Les anthologies en France. Paris: PUF, 1997.

GENETTE, Gérard. L'CEuvre de l'art, 1: immanence et transcendance. Paris: Seuil, 1994.

GRICE, H. Paul. Logique et conversation. Communications, v. 30, n. 30, p. 57-72, 1979.

HUOT, Sylvia. The scribe as editor, rubrication as critical apparatus in two manuscripts of the Roman de la Rose. L'Esprit Créateur, v. 27, n. 1, p. 67-78, 1987.

JONIN, Pierre. Anthologie thématique de la poésie française du Moyen Âge. Paris: H. Champion, 1991.

KRIPKE, Saul. La logique des noms propres. Paris: Minuit, 1985. (Naming and Necessity, Cambridge, Mass.: Harvard University Press 1980).

LÓPEZ MUÑOZ, Juan Manuel et al. La circulation des discours. Québec: Nota Bene, 2010.

. La circulation des travaux de Peytard en Espagne: lieux, 
temps, personnes, manières, fins. In: MADINI, M. et al. (Dir.). Jean Peytard: syntagmes et entailles. Besançon: P.U. Franche-Comté, 2013a. [en ligne].

. La mémoire des chansons de femme: objets, lieux et agents. Bref aperçu diachronique des anthologies de poésie française médiévale. Theorie, Littérature, Epistémologie, Presses Universitaires de Vincennes, n. 26 (Mémoire, savoir, innovation), p. 45-73, 2009.

La voix féminine de la littérature médiévale: du jeu de cacheLa antología cache à la nécessité de l'effacement. In: SUÁREZ, P. et al. (Dir.). Homo como un museo ludens, Homo loquens: le jeu de la parole au Moyen Âge. Madrid: S.P. de la Universidad Autónoma de Madrid, 2013b. [en ligne].

Messagers, porte-paroles et autres agents de la circulation des discours en ancien français littéraire: étude des Lais de Marie de France. L'Information Grammaticale, v. 118, p. 27-32, 2008.

MEYER, Paul. Documents manuscrits de l'ancienne littérature de la France conservés dans les bibliothèques de la Grande-Bretagne. Paris: Imprimerie Nationale, 1871.

PAVEAU, Marie Anne. Discours et cognition: les prédiscours entre cadres internes et environnement extérieur. Corela: Cognition, Représentation, Langage, numéro spécial, 2007. Disponível em: <http://corela.edel.univ-poitiers.fr/index.php?id=1550>. Acesso em: 15 jan. 2013.

PAVEAU, Marie Anne; ROSIER, Laurence. Le discours des objets: pratiques et techniques de circulation, entre clandestinité et exhibition discursive. Monográficos de Çedille, 1: la circulation des discours: médias, mémoire et croyances. 2010. [en ligne].

PERNOUD, Régine. La poésie médiévale française, Paris: Ed. du Chêne, 1947.

PEYTARD, Jean. D'une sémiotique de l'altération. Semen, n. 8, 1993. [en ligne]. 
POULAILLE, Henry; PERNOUD, Régine. Les chansons de toile, Paris: J. Rogers, 1947.

RABATEL, Alain (Dir.). Langages: Effacement énonciatif et discours rapportés, n. 156, 2004.

ROSENBERG, Samuel N.; TISCHLER, Hans. Chanter m'estuet: chansons des trouvères. Paris: Le Livre de Poche, 1995.

Juan Manuel THIRY, Claude (Dir.). Anthologie de la littérature francaise du Moyen López Muñoz Age, IXe-XVe siècles. Louvain-la-Neuve: Academia Bruylant, 2002.

108 WARNKE, Karl. Lais de Marie de France. Paris: Librairie Générale Française (Livre de Poche), 1990.

ZINK, Michel. Les chansons de toile. Paris: Champion, 1977. 